\title{
Recovery of muscle strength after microdiscectomy for lumbar disc herniation: a prospective cohort study with 1-year follow-up
}

\author{
Greger Lønne • Tore K. Solberg • Kristin Sjaavik • \\ Øystein P. Nygaard
}

Received: 7 June 2011/Revised: 25 November 2011/ Accepted: 7 December 2011/Published online: 23 December 2011

(C) Springer-Verlag 2011

\begin{abstract}
Background Surgery has not been proven to be a better treatment option than non-operative management for limb paresis due to lumbar disc herniation. For the patients it will still be a concern, whether they will regain full strength after the operation or not.

Methods A prospective cohort study of 91 patients with preoperative paresis due to disc herniation with 1-year follow up was carried out. The primary outcome was muscle strength in affected limb, and the secondary outcome was self-reported symptoms on back and leg pain, disability, health related quality of life, general health and working capability.

Results Seventy-five percent of patients had no paresis 1 year after the operation. The severity of the paresis was the only predictor for persistent paresis. Preoperative duration of the paresis did not influence the rate of full
\end{abstract}

\section{G. Lønne $(\bowtie)$}

Department of Orthopaedic Surgery, Innlandet Hospital Trust, Anders Sandvigsgt 17, Lillehammer 2609, Norway

e-mail: greger.lonne@ntnu.no

\section{G. Lønne · Ø. P. Nygaard}

Department of Neuroscience, Norwegian University of Science and Technology, Trondheim, Norway

T. K. Solberg · K. Sjaavik

Department of Neurosurgery, University Hospital of North

Norway, Troms $\emptyset$ 9038, Norway

T. K. Solberg · Ø. P. Nygaard

The Norwegian Registry for Spine Surgery (NORspine), North Norway Regional Health Authority, Troms $\varnothing$, Norway

$\varnothing$. P. Nygaard

Department of Neurosurgery, University Hospital of St. Olav, Olav Kyrresgt 17, Trondheim 7030, Norway recovery. Non-recovery was associated with inferior outcomes and higher risk for reduced working capability. Conclusions The majority of patients with paresis were fully recovered 1 year after microdiscectomy for lumbar disc herniation. If the paresis was severe at baseline, there was a four times higher risk for non-recovery. Patients who did not recover had significantly worse outcomes.

Keywords Lumbar spine - Disc herniation .

Microdiscectomy $\cdot$ Limb paresis · Intervertebral disk

\section{Introduction}

It has not been shown that surgery is better than nonsurgical management for treating limb paresis caused by lumbar disc herniation [1-3]. However in clinical practice, limb paresis is a frequent additional symptom to pain [4-7], and for the patients, a major concern remains: "What are the chances that my muscle strength will recover after surgery?". The aim of this study is to give an answer to this question. We also wanted to investigate if persisting paresis is associated to worse outcome measured by changes in physical function, health related quality of life (HRQL), pain, and working capability. Such information could be used in the decision-making process prior to surgery.

\section{Materials and methods}

Patient population

In this prospective cohort study we evaluated 403 consecutive patients operated for the first time with 
microdiscectomy for lumbar disc herniation. Of these patients, 91 had limb paresis and were included (Fig. 1). Patients with recurrent disc herniation after 3 months were considered as a new event and were excluded $(N=18)$. Reoperations before 3 months were classified as complications to the primary surgery, and these cases $(N=5)$ were included. All patients were operated at the Department of Neurosurgery, University Hospital of North Norway.

Data were collected in a comprehensive clinical spine surgery registry for quality control and research between 1st of January 2004 and 30th of September 2006. Follow up time from date of operation (baseline) was 1 year. Informed consent was obtained from all participants, and the Data Inspectorate in Norway had approved the clinical registry.

\section{Self-administered questionnaires}

The questionnaires completed by the patients at baseline and follow up were identical, and were used for outcome assessments. The baseline questionnaire included additional questions about demographics and lifestyle issues.

\section{Baseline data}

During the hospital stay, the doctor responsible for each patient made the clinical neurological examination of the patient, recorded data concerning diagnosis, treatment and employment status and duration of symptoms and sick leave according to the standard registration form. Finally all questionnaires and forms were collected and checked for completeness by a trained research nurse.

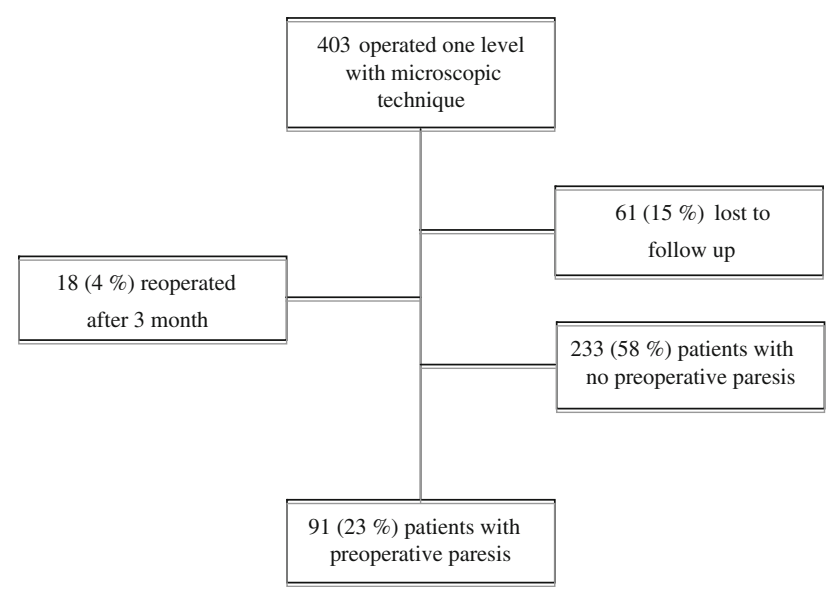

Fig. 1 Patient selection
Follow up data

Patients were summoned for follow up visits after 3 and 12 months at an outpatient clinic. Questionnaires were distributed by mail together with the appointment letters, and were completed at home by the patients. An independent observer (two trained research nurses) responsible for all follow up visits made the clinical neurological examination, then collected and checked all questionnaires.

\section{Primary outcome measurement}

The primary outcome measure was muscle strength of the affected limb. We used Daniels and Worthingham's techniques of manual muscle testing [8], which was graded to range from 0 to 5 . In this scale, grade 4 is " $50 \%$ reduction of force", grade 3 "ability to move against gravity", grade 2 "ability to move the limb or toe but not against gravity", grade 1 is "ability to produce visible muscle contraction, but no movement of the limb" and grade 0 is "no visible muscle contraction". Based on this scale we categorised the patients into three groups: severe paresis (grade 0-3), mild paresis (grade 4) and normal muscle strength (grade 5). Changes in motor function were classified as recovery (normal muscle strength) or non-recovery (incompletely improved, unchanged or worse).

\section{Secondary outcome measures}

Secondary outcome measures were HRQL (EQ-5D), oswestry disability index (ODI), visual analogue scale (VAS) for leg pain and back pain, EQ-5D VAS for general health state and employment status.

EQ-5D

EQ-5D is a generic and preference-weighted measure of HRQL. It evaluates five dimensions: mobility, self care, activities of daily life, pain and anxiety and/or depression. For each dimension, the patient describes three possible levels of problems (no, mild to moderate and severe). Hence, this descriptive system contains 243 combinations or index values for health states [9]. We used the value set based on the main survey from the EuroQol group [10, 11], which has been validated for this patient population [12]. Total score range is from -0.594 to 1 , where 1 corresponds to perfect health, and 0 to death.

\section{ODI}

Functional status was assessed by the Oswestry low back disability questionnaire which contains ten questions on the limitations of activities of daily living. Each variable is 
rated on a 0-5-point scale, added up and transferred into a percentage score, the ODI ranging from 0 to $100(0=$ no disability).

\section{Leg pain and low back pain}

The patient graded pain intensity for leg pain and back pain in two separate $100 \mathrm{~mm} \mathrm{VAS}$, endpoints were 0 (no pain) and 100 (worst conceivable pain).

Health state

EQ-5D VAS forms the second part of the EQ-5D questionnaire. The patients rated their general health state by drawing a line from a box marked "your health state today" to the appropriate point on the VAS scale which ranges from 0 to 100 (worst to best imaginable health).

\section{Duration of paresis}

This information was not a part of the standard questionnaire and was collected from the medical records.

\section{Employment status}

The research nurse interviewed the patients about employment status at follow up.

\section{Statistical analyses}

The zero-hypothesis is that there will be no difference in the paresis at baseline and 12 months of follow up.

Depending on the distribution of the data, we evaluated score changes of outcome measures within groups by paired sample Student's $t$ test or Wilcoxon signed rank test and differences between groups with independent samples $t$ test, Mann-Whitney $U$ tests or Chi-square tests. Risk factor assessment was made by univariate analyses (logistic regression) using recovery of full muscle strength (yes/no) as dependent variable and the severity of the paresis (mild/severe) as exposition variable. The Statistical Package for the Social Sciences (SPSS for Windows, version 16.0, Chicago, IL, USA) was used in all analyses.

\section{Results}

Study population

Characteristics of the study population at baseline are listed in Table 1. The preoperative investigation was MRI in 40 (44\%), CT in $32(35 \%)$ and in $19(21 \%)$ patients both methods were used. Five patients $(6 \%)$ were operated in level L3/L4, 46 (52\%) in level L4/L5 and 38 (43\%) in level L5/S1. Two patients were operated at two levels (2\%).

\section{Primary outcome}

At 12 months 68 patients $(75 \%)$ were fully recovered (Table 2). Out of 23 patients (25\%) who were not fully recovered, $9(10 \%)$ were improved and 14 (15\%) were unchanged. None got worse. Sixteen (55\%) out of 29 patients with severe paresis fully recovered whilst 52 $(84 \%)$ out of 62 patients with mild paresis fully recovered $(p=0.003)$. A severe paresis at baseline was the only independent risk factor we could find for not having full recovery of muscle function, odds ratio: 4.2 (95\% $\mathrm{CI}=1.6-11.4)$. Duration of the paresis was not associated with recovery. The mean (SD), duration of paresis was 30 (57) days. We evaluated several possible cut-offs for the duration of paresis, which could indicate a good or bad prognosis for recovery ( 2 days, median (6 days), 2 weeks, 1 month), but no statistically significant threshold was found.
Table 1 Characteristics of the study population at baseline, comparing recovery and nonrecovery group

$B M I$ body mass index

* $P$ values of differences between recover and nonrecover

${ }^{\text {a }}$ University or college education

\begin{tabular}{|c|c|c|c|c|}
\hline & $\begin{array}{l}\text { All patients } \\
(N=91)\end{array}$ & $\begin{array}{l}\text { Recovery } \\
\text { group }(n=68)\end{array}$ & $\begin{array}{l}\text { Non-recovery } \\
\text { group }(n=23)\end{array}$ & $P$ value* \\
\hline Age; mean (SD) (years) & $45(11)$ & $44.4(11)$ & $47.5(11)$ & 0.2 \\
\hline Females (\%) & $37(41)$ & $28(41)$ & $9(39)$ & 0.9 \\
\hline BMI; mean (SD) $\left(\mathrm{kg} / \mathrm{m}^{2}\right)$ & $25(4)$ & $25(3)$ & $26(4)$ & 0.3 \\
\hline Smokers; $n(\%)$ & $23(28)$ & $18(30)$ & $5(23)$ & 0.5 \\
\hline $\begin{array}{l}\text { Duration of paresis (days); } \\
\text { mean (median) }\end{array}$ & $30(6)$ & $32(6)$ & $23(9)$ & 0.9 \\
\hline $\begin{array}{l}\text { Weeks on sick leave before } \\
\text { operation; mean (SD) }\end{array}$ & $13(49)$ & $11(48)$. & $18(53)$ & 0.8 \\
\hline Duration of leg pain (weeks) & $14(29)$ & $16(32)$ & $11(12)$ & 0.8 \\
\hline Days of hospital stay & $3(2)$ & $3(2)$ & $3(1)$ & 0.7 \\
\hline \multicolumn{5}{|l|}{ Mean (median) } \\
\hline Educational level; $n(\%)^{\mathrm{a}}$ & $33(37)$ & $25(38)$ & $8(35)$ & 0.7 \\
\hline
\end{tabular}


Table 2 Number of patients with different degrees of paresis pre- and postoperation

\begin{tabular}{lllll}
\hline At baseline & \multicolumn{4}{l}{ 12 months after operation } \\
\hline Paresis & Severe & Mild & No paresis & Total $n(\%)$ \\
Severe & 5 & 8 & 16 & $29(32)$ \\
Mild & 0 & 10 & 52 & $62(68)$ \\
Total $n(\%)$ & $5(5)$ & $18(20)$ & $68(75)$ & $91(100)$ \\
\hline
\end{tabular}

Degree of paresis classified into full muscle strength (grade 5), mild paresis (grade 4) and severe paresis (grade 0-3)

Secondary outcome

For the whole study population, there was a statistically significant improvement of pain, functional status and HRQL and general health $(p<0.001)$. Patients who recovered had a significant better outcome than patients with persistent paresis, except for leg pain. Amongst those who did not recover, three times as many received workers compensation at 12 months follow up (57 vs. $20 \%, p=0.001$ ) (Table 3).

\section{Complications}

One patient had a dural tear, one had postoperative deep infection, and one had postoperative haematoma. None of them were re-operated. Five patients $(5 \%)$ had a new operation for herniated disc at the same level and side within 3 months after the primary surgery. Including all these cases, the complication rate was 9\% (eight patients).

\section{Discussion}

The surgical method used in this study, microdiscectomy, seems to be the preferred method in many publications [1317], and has fewer complications than other methods [18].

This study shows that $75 \%$ of the patients with limb paresis due to herniated lumbar disc had full recovery 12 months after micro discectomy. Patients with mild paresis can be informed that they have a good chance to recover $(84 \%)$. Patients with severe paresis have less, but still a good chance to recover (55\%). Fifteen percent had some improvement but not complete remission, and $10 \%$ had no improvement. The recovery rate was similar to the results published earlier [2, 6, 19, 20]. Previous studies evaluating more severe paresis (grade 3 or worse) show similar associations between the severity of paresis and the recovery rate $[5,7,21]$.

In this study, the method for measuring paresis was subjective, as in previous studies. The clinical information obtained by manual testing are not inferior to those given by EMG [7], provided that the assessment of muscle strength is made using standard methods. We followed the principle of Daniels and Worthingham's muscle testing [8]. We classified the degree of paresis into three different groups to make it simple and more reliable. It may be easier to measure the strength of L5 more precise than L4 and S1. A weakness of our study is that different investigators did the baseline examination and the follow up. Furthermore we have not performed an inter- or intraobserver study on the manual testing.
Table 3 Difference (mean) between non-recovery group and recovery group at baseline, 3 months and at 12 months follow up

\begin{tabular}{lllll}
\hline Test & $\begin{array}{l}\text { Test point } \\
\text { (months) }\end{array}$ & $\begin{array}{l}\text { Non-recovery } \\
\text { group }\end{array}$ & $\begin{array}{l}\text { Recovery } \\
\text { group }\end{array}$ & $\begin{array}{l}\text { Sig. } \\
(2 \text {-tailed })\end{array}$ \\
\hline Low back pain (VAS $)$; mean (SD) & Baseline & $51(25)$ & $50(31)$ & 0.9 \\
& 3 & $34(26)$ & $24(23)$ & 0.1 \\
Leg pain (VAS); mean (SD) & 12 & $43(30)$ & $22(23)$ & 0.001 \\
& Baseline & $64(27)$ & $65(27)$ & 0.9 \\
& 3 & $21(27)$ & $16(18)$ & 0.3 \\
Oswestry disability index; mean (SD) & 12 & $26(31)$ & $17(19)$ & 0.1 \\
& Baseline & $53(17)$ & $45(22)$ & 0.1 \\
EQ-5D; mean (SD) & 3 & $21(15)$ & $16(13)$ & 0.2 \\
& 12 & $28(22)$ & $14(14)$ & 0.001 \\
General health (VAS); mean (SD) & Baseline & $0.17(0.37)$ & $0.25(0.37)$ & 0.4 \\
& 3 & $0.65(0.23)$ & $0.71(0.24)$ & 0.3 \\
& 12 & $0.52(0.35)$ & $0.73(0.25)$ & 0.003 \\
& Baseline & $46(24)$ & $46(24)$ & 1.0 \\
Received workers compensation & \\
& 3 & $64(20)$ & $74(18)$ & 0.026 \\
& 12 & $58(25)$ & $76(20)$ & 0.001 \\
& Baseline & $14(61)$ & $40(59)$ & 0.9 \\
& 3 & $17(74)$ & $32(38)$ & 0.065 \\
& 12 & $13(57)$ & $13(20)$ & 0.001 \\
\hline
\end{tabular}


Our study was not designed to compare surgical and nonsurgical treatment (no control group). We do not know the fate of the paresis if the patient had not been operated. An open prospective multicentre study by Dubourg et al. [2] showed no difference in recovery rates after surgical and non-operative treatment. However, in this study there was a selection bias, since surgically treated patients had a higher rate of extruded herniation, higher numbers of paretic muscles and longer duration of sciatica. There was also $40 \%$ crossover from the non-surgical to the surgical group.

Only the severity of the paresis was identified as an independent risk factor for non-recovery. Surprisingly, there was no association between the preoperative duration of the muscle weakness and recovery, and we could not identify any cut-off in duration of paresis that would indicate a good or poor prognosis for recovery. This is an important finding which does not support the concept that the best effect of surgery is obtained in patients with short duration of paresis. The size of our sample might, however, have an impact upon this finding. We did not look at patients with paresis less than 24-h duration, since duration of paresis in this study was difficult to define in terms of hours.

The non-recovery group had significantly less improvement in ODI, EQ-5D, back pain, general health, and working capability at 12 months of follow up, and these associations indicate that persistent paresis represents a significant and complex problem for the patients.

\section{Conclusion}

In general, patients have a $75 \%$ chance of recovery from a limb paresis after surgical treatment for lumbar disc herniation. Patients with mild paresis can be informed that they have a good chance to recover (84\%). Patients with severe paresis have less good chance to recover $(55 \%)$. Persisting paresis seems to have a significant negative impact on the physical function and HRQL. There was no association between the preoperative duration of the muscle weakness and recovery.

\section{Conflict of interest None.}

\section{References}

1. Cribb GL, Jaffray DC, Cassar-Pullicino VN (2007) Observations on the natural history of massive lumbar disc herniation. J Bone Joint Surg Br 89:782-784. doi:10.1302/0301-620X.89B6.18712

2. Dubourg G, Rozenberg S, Fautrel B, Valls-Bellec I, Bissery A, Lang T, Faillot T, Duplan B, Briançon D, Levy-Weil F, Morlock G, Crouzet J, Gatfosse M, Bonnet C, Houvenagel E, Hary S, Brocq O, Poiraudeau S, Beaudreuil J, de Sauverzac C, Durieux S, Levade M-H, Esposito P, Maitrot D, Goupille P, Valat J-P, Bourgeois P
(2002) A pilot study on the recovery from paresis after lumbar disc herniation. Spine 27:1426-1431 (discussion 1431)

3. Weber H (1983) Lumbar disc herniation: a controlled, prospective study with ten years of observation. Spine 8:131-140

4. Barth M, Weiss C, Thomé C (2008) Two-year outcome after lumbar microdiscectomy versus microscopic sequestrectomy: part 1: evaluation of clinical outcome. Spine 33:265-272. doi:10.1097/BRS.0b013e318162018c

5. Eysel P, Rompe JD, Hopf C (1994) Prognostic criteria of discogenic paresis. Eur Spine J 3:214-218

6. Mariconda M, Galasso O, Secondulfo V, Cozzolino A, Milano C (2008) The functional relevance of neurological recovery after lumbar discectomy: a follow-up of more than 20 years. J Bone Joint Surg Br 90:622-628. doi:10.1302/0301-620X.90B5.20182

7. Postacchini F, Giannicola G, Cinotti G (2002) Recovery of motor deficits after microdiscectomy for lumbar disc herniation. J Bone Joint Surg Br 84:1040-1045

8. Hislop H, Montgomery J, H. Connolly B, Daniels L (2007) Daniels and Worthingham's muscle testing: techniques of manual examination, 8th edn. p 437

9. Group TE (1990) EuroQol: a new facility for the measurement of health-related quality of life. Health Policy 16:199-208

10. Dolan P (1997) Modeling valuations for EuroQol health states. Med Care 35:1095-1108

11. Kind P, Dolan P, Gudex C, Williams A (1998) Variations in population health status: results from a United Kingdom national questionnaire survey. BMJ 316:736-741

12. Solberg TK, Olsen J-A, Ingebrigtsen T, Hofoss D, Nygaard OP (2005) Health-related quality of life assessment by the EuroQol$5 \mathrm{D}$ can provide cost-utility data in the field of low-back surgery. Eur Spine J 14:1000-1007. doi:10.1007/s00586-005-0898-2

13. Arts M, Brand R, van der Kallen B, Lycklama a Nijeholt G, Peul W (2011) Does minimally invasive lumbar disc surgery result in less muscle injury than conventional surgery? A randomized controlled trial. Eur Spine J 20:51-57. doi:10.1007/s00586-010-1482-y

14. Veresciagina K, Spakauskas B, Ambrozaitis KV (2010) Clinical outcomes of patients with lumbar disc herniation, selected for one-level open-discectomy and microdiscectomy. Eur Spine J 19:1450-1458. doi:10.1007/s00586-010-1431-9

15. Porchet F, Bartanusz V, Kleinstueck FS, Lattig F, Jeszenszky D, Grob D, Mannion AF (2009) Microdiscectomy compared with standard discectomy: an old problem revisited with new outcome measures within the framework of a spine surgical registry. Eur Spine J 18(3):360-366. doi:10.1007/s00586-009-0917-9

16. Brock M, Kunkel P, Papavero L (2008) Lumbar microdiscectomy: subperiosteal versus transmuscular approach and influence on the early postoperative analgesic consumption. Eur Spine J 17:518-522. doi: $10.1007 / \mathrm{s} 00586-008-0604-2$

17. Silverplats K, Lind B, Zoega B, Halldin K, Rutberg L, Gellerstedt M, Brisby H (2010) Clinical factors of importance for outcome after lumbar disc herniation surgery: long-term follow-up. Eur Spine J 19:1459-1467. doi:10.1007/s00586-010-1433-7

18. Teli M, Lovi A, Brayda-Bruno M, Zagra A, Corriero A, Giudici F, Minoia L (2010) Higher risk of dural tears and recurrent herniation with lumbar micro-endoscopic discectomy. Eur Spine J 19:443-450. doi:10.1007/s00586-010-1290-4

19. Dewing CB, Provencher MT, Riffenburgh RH, Kerr S, Manos RE (2008) The outcomes of lumbar microdiscectomy in a young, active population: correlation by herniation type and level. Spine 33:33-38. doi:10.1097/BRS.0b013e31815e3a42

20. Jönsson B, Strömqvist B (1995) Motor affliction of the L5 nerve root in lumbar nerve root compression syndromes. Spine 20:2012-2015

21. Suzuki A, Matsumura A, Konishi S, Terai H, Tsujio T, Dozono S, Nakamura H (2011) Risk factor analysis for motor deficit and delayed recovery associated with L4/5 lumbar disc herniation. J Spinal Disord Tech 24:1-5. doi:10.1097/BSD.0b013e3181c5be1d 